\title{
Métodos para determinação da digestibilidade aparente de dietas para camarão marinho suplementadas com probiótico
}

\author{
Celso Buglione-Neto(1), José Luiz Mouriño(2), Felipe do Nascimento Vieira(2), Bruno Corrêa da Silva(2), \\ Adolfo Jatobá(3), Walter Seiffert( ${ }^{(2)}$, Débora Machado Fracalossi( ${ }^{(4)}$ e Edemar Andreatta ${ }^{(2)}$
}

\begin{abstract}
(1)Usina Hidrelétrica de Itaipu, Avenida Tancredo Neves, no 6.731, CEP 85856-970 Foz do Iguaçu, PR. E-mail: celsoc@itaipu.gov.br (2)Universidade Federal de Santa Catarina (UFSC), Centro de Ciências Agrárias (CCA), Departamento de Aquicultura (AQI), Laboratório de Camarões Marinhos, Beco dos Coroas, Barra da Lagoa, CEP 88061-600 Florianópolis, SC. E-mail: mourino@lcm.ufsc.br, vieirafn@lcm.ufsc.br, bcs85@hotmail.com, seiffert@cca.ufsc.br, andreata@mbox1.ufsc.br (3)Instituto Federal Catarinense, Campus Araquari, Rodovia BR-280, Km 27, CEP 89245-000 Araquari, SC. E-mail: adolfo.jatoba@ifc-araquari.edu.br (4)UFSC, CCA, AQI, Laboratório de Nutrição de Organismos Aquáticos, Rodovia Admar Gonzaga, o⒈346, CEP 88034-001 Florianópolis, SC. E-mail: deboraf@cca.ufsc.br
\end{abstract}

Resumo - O objetivo deste trabalho foi determinar o método de coleta de fezes mais adequado para camarões marinhos (Litopenaeus vannamei) na determinação do coeficiente de digestibilidade aparente da proteína bruta e da matéria seca de dietas comerciais, e avaliar o efeito da suplementação de Lactobacillus plantarum na dieta sobre o coeficiente de digestibilidade aparente da proteína, da energia e da matéria seca. Foram testados três sistemas de coletas de fezes: decantação, sifonamento e dissecação dos animais. A coleta por decantação foi o sistema mais adequado para a determinação in vivo dos coeficientes de digestibilidade aparente da proteína bruta e da matéria seca das dietas, por apresentar baixo grau de lixiviação das fezes e por ser de fácil execução. Nos camarões alimentados com a dieta suplementada com L. plantarum, foi observado maior coeficiente de digestibilidade aparente da proteína $(84,18 \pm 0,35 \%)$ e da energia $(81,28 \pm 0,16 \%)$, quando comparado ao grupo controle $(82,73 \pm 1,01$ e $78,63 \pm 0,93 \%$, respectivamente). O uso de $L$. plantarum como aditivo probiótico na ração pode trazer benefícios nutricionais a $L$. vannamei, com melhor aproveitamento dos nutrientes.

Termos para indexação: Lactobacillus plantarum, Litopenaeus vannamei, digestibilidade, nutrição.

\section{Methods for determining the apparent digestibility of diets for marine shrimp supplemented with probiotic}

\begin{abstract}
The objective of this work was to determine the most adequate feces collection method for sea shrimp (Litopenaeus vannamei) in the determination of the apparent digestibility coefficients of crude protein and dry matter of commercial diets, and to evaluate the effect of supplementation of Lactobacillus plantarum to the diet on the apparent digestibility coefficient of protein, energy, and dry matter. Three feces collection methods were tested: decanting, siphoning, and animal dissection. Decanting was the method best suited for the in vivo determination of the apparent digestibility coeffcients of crude protein and dry matter of commercial diets, since it promoted lower nutrient leaching from feces and was easy to perform. Shrimp fed the diet supplemented with probiotic showed higher apparent digestibility of crude protein $(84.18 \pm 0.35 \%)$ and energy $(81.28 \pm 0.16 \%)$ when compared to the control group $(82.73 \pm 1.01$ and $78.63 \pm 0.93 \%$, respectively). The use of L. plantarum as a probiotic additive in shrimp diets can provide nutritional benefits to L. vannamei, with better nutrient utilization.
\end{abstract}

Index terms: Lactobacillus plantarum, Litopenaeus vannamei, digestibility, nutrition.

\section{Introdução}

Com a intensificação dos sistemas de cultivo e a rápida expansão da carcinicultura, há uma demanda cada vez maior por dietas nutricionalmente balanceadas e com custo acessível (Bautista-Teruel et al., 2003). A ração representa cerca de $60 \%$ dos custos variáveis nos cultivos de camarão, nos sistemas semi-intensivos (Lawrence \& Lee, 1997). Portanto, tem-se buscado reduzir o custo da ração, com o melhor aproveitamento das fontes proteicas (Lemos et al., 2009). O uso de aditivos alimentares, como os probióticos, torna-se uma alternativa para aumentar a digestibilidade dos nutrientes na dieta, concomitantemente ao aumento da imunidade dos animais, o que diminui os custos da carcinicultura (Ochoa-Solano \& Olmos-Soto, 2006; Vieira et al., 2008; Zhou et al., 2009).

Vieira (2010), ao avaliar a bactéria Lactobacillus plantarum [(Orla-Jensen) Bergey et al.] do trato intestinal de Litopenaeus vannamei (Boone, 1931), 
observou efeito probiótico, evidenciado pelo aumento da sobrevivência e da imunidade dos camarões após desafio experimental com Vibrio harveyi [(Johnson and Shunk 1936) Baumann et al. 1981], além de melhoria na eficiência alimentar em animais cultivados em campo. Porém, não foi comprovado se o aumento da eficiência alimentar se deu pela maior digestibilidade dos ingredientes da dieta.

Diversos estudos avaliaram a utilização de probióticos para melhorar a capacidade digestiva de animais aquáticos (Burr et al., 2005). A adição de bactérias do gênero Bacillus em L. vannamei aumentou a atividade de amilases e proteases dos camarões, o que melhorou a digestão e a absorção dos alimentos, que, por sua vez, contribuiu para a melhoria no crescimento dos camarões (Yu et al., 2009).

A digestibilidade in vivo em animais aquáticos é baseada na determinação da quantidade do marcador inerte - como, por exemplo, o óxido de cromo $\left(\mathrm{Cr}_{2} \mathrm{O}_{3}\right)$ - nas fezes, o qual é incorporado na ração. Entretanto, para o uso deste método, é essencial que se tenha um sistema eficiente de coleta de fezes no meio aquático (Martínez-Palacios et al., 2001).

O sistema mais simples de coleta fecal é o sifonamento do material do fundo do tanque ou aquário. No entanto, esta técnica está sujeita a numerosos erros, entre eles a lixiviação dos nutrientes e da matéria seca para a água, o que pode superestimar os valores alcançados (Mouriño \& De Stéfani, 2006).

Já o Guelph (coleta por decantação), é um sistema eficiente desenvolvido para peixes, que utiliza um fluxo de água com baixa velocidade, de forma que as fezes decantem mais rapidamente no centro do tanque, para serem recolhidas em tubo coletor. Este sistema funciona bem para diversos organismos aquáticos e, portanto, é amplamente utilizado (Cho et al., 1985; Mouriño \& De Stéfani, 2006).

Contudo, ensaios de digestibilidade in vivo apresentam algumas peculiaridades, pois os camarões têm hábitos bentônicos, são coprófagos e alimentamse lentamente (Smith \& Tabrett, 2004). Como consequência, a digestibilidade em camarões foi avaliada por sifonamento das fezes (Cruz-Suárez et al., 2009; Terrazas-Fierro et al., 2010).

O objetivo deste trabalho foi determinar o método de coleta de fezes mais adequado para camarões marinhos na determinação do coeficiente de digestibilidade aparente da proteína bruta e da matéria seca de dietas comerciais, e avaliar a suplementação de Lactobacillus plantarum na dieta sobre o coeficiente de digestibilidade aparente da proteína, da energia e da matéria seca.

\section{Material e Métodos}

Os experimentos foram realizados no Laboratório de Camarões Marinhos da Universidade Federal de Santa Catarina (UFSC), em Florianópolis.

Para a determinação do tempo de passagem e esvaziamento gástrico, foram utilizados 30 camarões com peso médio de $8,0 \pm 0,5 \mathrm{~g}$. Os camarões foram alimentados com ração comercial e, após o décimo dia, iniciou-se a alimentação com dieta contendo $0,5 \%$ de óxido de cromo $\left(\mathrm{Cr}_{2} \mathrm{O}_{3}\right)$ como marcador inerte (Tabela 1). As fezes foram coletadas em intervalos de 30 min, e, quando observada a presença da coloração verde nas fezes, foi determinado o tempo de passagem. Para a determinação do tempo de esvaziamento gástrico, suspendeu-se o fornecimento da dieta $\mathrm{e}$ monitorou-se a produção de fezes de hora em hora, até o término da produção de fezes.

Para a avaliação dos métodos de coletas de fezes, foram utilizados 120 camarões com peso médio de $8,0 \pm 0,5$ g. Foram testados três sistemas de coleta das fezes, em triplicata: sedimentação, em tanques cilindro-cônicos com tela; sifonamento, em tanques circulares, com fundo parabólico; e coleta por dissecação dos animais.

A densidade utilizada foi de 20 animais por tanque de $100 \mathrm{~L}$, a qual foi determinada em ensaios anteriores. Foram avaliados os coeficientes de digestibilidade aparente da proteína bruta e da matéria seca da dieta comercial.

Antes de iniciar a coleta de fezes, os camarões foram aclimatados às condições experimentais por dez dias, tendo recebido ração comercial suplementada

Tabela 1. Composição centesimal das dietas utilizadas nos experimentos.

\begin{tabular}{lccc}
\hline Fração & Ração comercial & Controle & Probiótico \\
\hline Proteína bruta $\left(\mathrm{g} \mathrm{kg}^{-1}\right)$ & $346,7 \pm 0,5 \mathrm{~b}$ & $360,3 \pm 4,7 \mathrm{a}$ & $362,2 \pm 2,5 \mathrm{a}$ \\
Extrato etéreo $\left(\mathrm{g} \mathrm{kg}^{-1}\right)$ & $75,0 \pm 1,2$ & $74,2 \pm 1,6$ & $74,7 \pm 0,8$ \\
Fibra em detergente ácido $\left(\mathrm{g} \mathrm{kg}^{-1}\right)$ & $50,1 \pm 0,4$ & $45,8 \pm 0,7$ & $45,5 \pm 0,8$ \\
Matéria mineral $\left(\mathrm{g} \mathrm{kg}^{-1}\right)$ & $130,2 \pm 1,5$ & $129,8 \pm 1,3$ & $128,1 \pm 1,2$ \\
Matéria seca $\left(\mathrm{g} \mathrm{kg}^{-1}\right)$ & $954,8 \pm 3,4 \mathrm{~b}$ & $935,9 \pm 5,4 \mathrm{a}$ & $936,4 \pm 10,9 \mathrm{a}$ \\
Óxido de cromo $\left(\mathrm{g} \mathrm{kg}^{-1}\right)$ & & $0,5 \%$ & $0,5 \%$ \\
Energia $(\mathrm{kcal})$ & $3.259,3 \pm 55,9 \mathrm{~b}$ & $3.775,9 \pm 109,5 \mathrm{a}$ & $4080,1 \pm 222,4 \mathrm{a}$ \\
\hline
\end{tabular}


com $0,5 \%$ de óxido de cromo como marcador inerte. A ração foi oferecida em três alimentações diárias (às $8 \mathrm{~h}$, às $14 \mathrm{~h}$ e às $20 \mathrm{~h}$ ), em bandejas, de forma a totalizar $3 \%$ da biomassa total de cada tanque. O tempo de alimentação foi de $40 \mathrm{~min}$, e, após este período, a bandeja de alimentação era retirada para a higienização dos tanques antes da coleta das fezes. O período total de coleta foi de 15 dias.

Para a coleta por decantação, foram utilizados três tanques cilindro-cônicos com capacidade de $100 \mathrm{~L}$ e temperatura constante de $28^{\circ} \mathrm{C}$ (Figura 1), contendo gaiolas povoadas com 20 camarões cada uma $(n=60)$. As fezes foram coletadas na extremidade inferior do tanque, onde permaneciam depositadas em tubos de $50 \mathrm{~mL}$, acoplados a um registro de esfera. Os tubos contendo as fezes eram retirados em intervalos de 30 min e contados a partir da retirada da bandeja de alimentação, para não haver lixiviação de nutrientes para a água. As fezes coletadas eram, então, armazenadas a $-20^{\circ} \mathrm{C}$ até análise.

Para a coleta por sifonamento (Figura 1), foram utilizados três tanques cilindro-cônicos com capacidade de $100 \mathrm{~L}$ e temperatura constante de $28^{\circ} \mathrm{C}$. Cada tanque continha uma gaiola, povoada com 20 camarões $(n=60)$, um cano central e um dreno com tela de $500 \mu \mathrm{m}$ para renovação da água. Nestes tanques, a renovação de água foi constante $\left(1 \mathrm{~L} \mathrm{~min}^{-1}\right)$. $\mathrm{O}$ tanque tinha fundo cônico, e as fezes se acumulavam próximo ao dreno central, em razão da corrente circular dentro do tanque. As fezes foram coletadas por sifonamento

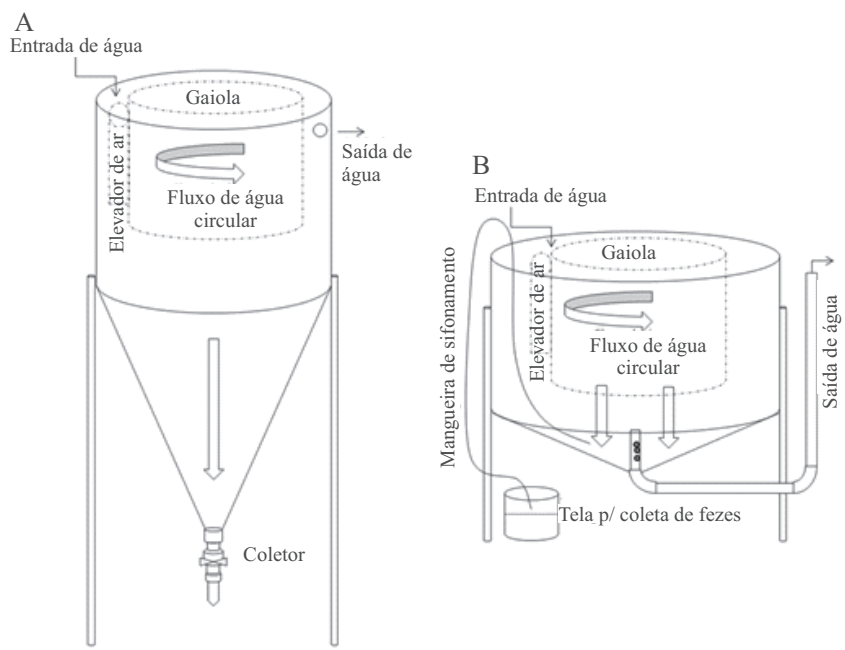

Figura 1. Métodos de coleta de fezes de camarões marinhos. A, sistema de coleta por decantação; B, sistema de coleta por sifonamento. do fundo do tanque com o auxílio de mangueira de silicone ( $5 \mathrm{~mm}$ de diâmetro) e uma tela de $40 \mu \mathrm{m}$, em intervalos de $30 \mathrm{~min}$, para evitar a lixiviação de nutrientes para a água. As fezes eram retiradas da tela com o auxílio de uma pinça e armazenadas em potes de plástico, a $-20^{\circ} \mathrm{C}$, até análise.

Para a coleta de fezes por dissecação, foram utilizados três tanques circulares de $8.000 \mathrm{~L}$, contendo 200 camarões por tanque $(n=600)$, com renovação constante, fluxo de água a $1 \mathrm{~L} \mathrm{~min}^{-1}$ e temperatura de $28^{\circ} \mathrm{C}$. Após sete dias de aclimatação, estes camarões foram alimentados durante dez dias com ração contendo $0,5 \%$ de óxido de cromo. Após este período, os camarões foram abatidos por hipotermia, com uso de $2 \mathrm{~kg}$ de gelo e $1 \mathrm{~L}$ de água para cada quilo de camarão. Foi realizado um corte no último segmento abdominal de cada camarão, e as fezes contidas no intestino foram retiradas após leve pressão no sentido do último segmento, de modo a forçar sua saída pelo corte. O material foi coletado com o auxílio de uma pinça, colocado em um recipiente e congelado a $-20^{\circ} \mathrm{C}$ até análise.

A cepa probiótica, Lactobacillus plantarum (CPQBA 007-07 DRM01), utilizada para os ensaios, foi isolada de camarões marinhos (Vieira, 2010) e cedida pelo Laboratório de Camarões Marinhos da UFSC. A cepa bacteriana foi repicada em tubos de ensaio contendo caldo de Man, Rogosa e Sharpe (MRS, Difco, Detroit, MI, EUA) e incubada com agitação contínua de $200 \mathrm{rpm}$, a $35^{\circ} \mathrm{C}$, por 24 horas. A contagem de unidades formadoras de colônias (UFC) em Agar

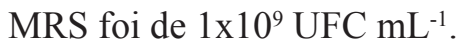

Para o preparo das dietas experimentais, foi utilizada ração comercial contendo $0,5 \%$ de óxido de cromo, a qual foi aspergida com $200 \mathrm{~mL} \mathrm{~kg}^{-1}$ de inóculo das bactérias ácido-lácticas e desidratada, a $35^{\circ} \mathrm{C}$, por 24 horas (dieta probiótica). Três amostras de $1 \mathrm{~g}$ da ração seca foram maceradas em $1 \mathrm{~mL}$ de solução salina $(1,5 \% \mathrm{NaCl})$ estéril e diluídas em série (1:10). As diluições $10^{-5}$ até $10^{-9}$ foram semeadas em placas com meio de cultura MRS e incubadas a $35^{\circ} \mathrm{C}$, por 48 horas, para estimar a contagem de UFC de bactérias probióticas na dieta. A ração controle passou pelo mesmo processo da ração suplementada com probióticos; porém, foi aspergida somente com meio de cultura estéril (dieta controle). Após esses procedimentos, as dietas experimentais, controle e 
probiótica foram submetidas a análises de composição centesimal (Tabela 1).

Para cada tratamento (dieta com probiótico e controle), foram utilizados quatro tanques de formato cilindro-cônico com capacidade para $100 \mathrm{~L}$, cada um contendo 20 camarões, com peso médio de $10 \pm 0,02 \mathrm{~g}$. O método de coleta de fezes foi o mesmo utilizado no sistema de decantação. Coletou-se um total de $6 \mathrm{~g}$ de fezes (peso seco), por réplica.

Para determinar a eficiência da colonização do probiótico nos animais, foram retiradas amostras de trato digestório, após total esvaziamento gástrico. Estas amostras foram lavadas com solução salina estéril e maceradas, para serem diluídas na proporção 1:1, em solução salina estéril $(1,5 \% \mathrm{NaCl})$, e diluídas em série $1: 10$. As diluições $10^{-5}$ e $10^{-9}$ foram semeadas em placas com meio de cultura MRS e incubadas a $35^{\circ} \mathrm{C}$, por 48 horas, para estimar a contagem de UFC de bactérias ácido-lácticas totais presentes no trato digestório.

Para a determinação do coeficiente de digestibilidade aparente de proteína, energia e matéria seca, as análises dos teores de proteína bruta, energia e matéria seca das rações e das fezes dos camarões seguiram a metodologia descrita pela AOAC (Cunniff, 1999). A matéria seca foi obtida após secagem a $105^{\circ} \mathrm{C}$ até peso constante; a cinza, após queima a $550^{\circ} \mathrm{C}$; a proteína bruta, pelo método Kjeldahl ( $\mathrm{N}$ x 6,25); o extrato etéreo, pelo método Soxleth, após hidrólise ácida; e a fibra, em detergente ácido. A energia bruta foi determinada em bomba calorimétrica adiabática, e o óxido de cromo, pelo método colorimétrico proposto por Bremer Neto et al. (2003) (Tabela 1). Nas fezes, foram analisados matéria seca, proteína bruta, energia bruta e óxido de cromo. Para a quantificação do óxido de cromo, as amostras das dietas e das fezes $(0,1 \mathrm{~g})$ foram digeridas com $3 \mathrm{~mL}$ de ácido nítrico e $2 \mathrm{~mL}$ de ácido perclórico em balões Kjeldahl, a $400^{\circ} \mathrm{C}$, por $40 \mathrm{~min}$, até obtenção de uma coloração amarelada. Após diluição em $1 \mathrm{~L}$ de água destilada, a absorbância foi lida $(550 \mathrm{~nm})$ e a concentração de óxido de cromo foi determinada pela comparação com a dosagem de uma curva-padrão.

Para a determinação do coeficiente de digestibilidade da matéria seca (CDAMS), foi utilizada a equação (Belal, 2005): CDA $(\%)=100-100 \times \%$ indicador na ração/\%indicador nas fezes.

Para a determinação do coeficiente de digestibilidade da proteína bruta (CDAPB) e do coeficiente de digestibilidade da energia (CDAE), foi utilizada a equação (Nose, 1960): CDA $(\%)=100-(100 \times \%$ marcador na dieta $/ \%$ marcador nas fezes $\times \%$ proteína ou energia nas fezes $/ \%$ proteína ou energia na dieta.

Todos os dados foram submetidos ao teste de Bartlett e apresentaram homocedasticidade. Os dados de avaliação dos diferentes métodos de coleta foram submetidos à análise de variância e, posteriormente, ao teste de Tukey. Os dados de digestibilidade aparente das dietas suplementadas com probiótico foram analisados pelo teste t. Foram admitidas diferenças significativas a $5 \%$ de probabilidade.

\section{Resultados e Discussão}

Para camarões L. vannamei com aproximadamente $8 \mathrm{~g}$, o tempo de passagem médio foi de $42 \pm 4 \mathrm{~min}$ e o tempo de esvaziamento gástrico de $376 \pm 15$ min. Contudo, a maior produção de fezes ocorreu 1 hora após o início da defecação e terminou após, aproximadamente, 6 horas. Segundo Cockcroft \& McLachlan (1986), juvenis e adultos de Macropetasma africanus (Balss, 1913) esvaziam o intestino entre 2 e 4 horas após a captura. Já para Penaeus subtilis (Pérez-Farfante, 1967), a taxa média de esvaziamento gástrico é de $28 \%$ por hora, o que totaliza 3 horas e 34 min (Nunes \& Parsons, 2000). Para L. vannamei de 14 a $22 \mathrm{~g}$, o tempo de esvaziamento gástrico foi de até 4 horas e $18 \mathrm{~min}$ (258 $\mathrm{min}$ ) (Faroongsarmg et al., 2007).

Não foram observadas diferenças significativas quanto ao CDAPB entre o sistema de coleta por sifonamento e decantação (Tabela 2). Este resultado evidencia que os dois sistemas são adequados para a estimativa do CDAPB. Entretanto, houve diferença significativa entre estes dois sistemas em relação ao CDAMS, e o sistema de sifonamento foi $2 \%$ superior ao de decantação (Tabela 2). Dessa forma, o sistema

Tabela 2. Média \pm desvio-padrão dos coeficientes de digestibilidade aparente de proteína e matéria seca em camarões marinhos, Litopenaeus vannamei, nos três sistemas de coleta de fezes ${ }^{(1)}$.

\begin{tabular}{lcc}
\hline Sistema de coleta de fezes & \multicolumn{2}{c}{ Coeficiente de digestibilidade aparente (\%) } \\
\cline { 2 - 3 } & \multicolumn{1}{c}{ Proteína } & Matéria seca \\
\hline Decantação & $81,83 \pm 0,59 \mathrm{a}$ & $59,53 \pm 0,69 \mathrm{a}$ \\
Sifonamento & $82,74 \pm 0,63 \mathrm{a}$ & $61,53 \pm 0,84 \mathrm{~b}$ \\
Dissecação & $55,65 \pm 0,78 \mathrm{~b}$ & $54,21 \pm 1,19 \mathrm{c}$ \\
\hline
\end{tabular}

${ }^{(1)}$ Médias seguidas de letras diferentes diferem pela análise de variância, a $5 \%$ de probabilidade. 
de coleta por sifonamento apresentou maior grau de desintegração das fezes, pois quando estas eram retidas na tela de coleta ficavam sujeitas a maior lixiviação pelo fluxo de água corrente, o que resultou em um maior CDAMS para este sistema de coleta.

O sistema de coleta por dissecação apresentou menor CDAPB e CDAMS quando comparado aos outros dois sistemas (Tabela 2). Neste método, foi observada maior dificuldade para obtenção da quantidade mínima de fezes, para análises de óxido de cromo e proteína bruta, em razão da pequena quantidade de material encontrada nos segmentos finais do trato digestório. Os resultados obtidos com esta metodologia podem estar subestimados pela possível contaminação das fezes com hemolinfa ou mucosa do intestino. Resultado semelhante foi verificado por Mouriño \& De Stéfani (2006), ao avaliar métodos de coleta de fezes para determinação da digestibilidade proteica em rã-touro [Rana catesbeiana (Shaw, 1802)]. De acordo com estes autores, a pressão durante a dissecação pode provocar, ocasionalmente, injúrias nas vísceras e promover a adição de nitrogênio endógeno às fezes na forma de muco e células epiteliais, o que diminui os valores da digestibilidade.

Assim, o sistema de coleta por decantação foi o que se adequou melhor às condições experimentais, para a determinação in vivo do CDAPB e do CDAMS de dietas para camarões marinhos, pois foi de fácil execução, promoveu menor grau de lixiviação das fezes, comparado ao sinfonamento, e não há a necessidade de sacrifício dos animais, como no sistema de dissecação. Martínez-Palacios et al. (2001) também relataram que o método Guelph (coleta por decantação) foi mais prático e eficiente do que o método de sifonamento para determinação da digestibilidade de proteína e lipídio, para camarão marinho.

Após o processo de incorporação da bactéria na dieta, a contagem de UFC em Agar MRS foi de $1,5 \times 10^{6} \mathrm{UFC} \mathrm{g}^{-1}$, na ração com probiótico, e de $1,4 \times 10^{6} \mathrm{UFC}^{-1}$ no trato intestinal dos camarões marinhos alimentados com esta dieta. Entretanto, os camarões alimentados com a dieta controle não apresentaram crescimento de bactérias ácido-lácticas em Agar MRS. Vieira et al. (2008) comprovaram que o fornecimento de dietas contendo L. plantarum para $L$. vannamei aumenta a contagem de bactérias ácido-láticas no trato intestinal dos camarões, o que, por sua vez, melhoria os parâmetros imunológicos dos animais frente à resistência após desafio com $V$. harveyi.

O grupo de camarões que recebeu dieta suplementada com L. plantarum apresentou maior CDAPB e CDAE, em comparação ao controle. Não foram observadas diferenças significativas quanto ao CDAMS entre os camarões alimentados com dieta suplementada ou não com probiótico (Tabela 3 ).

Esses aumentos no CDAPB e no CDAE podem estar relacionados a uma melhoria no equilíbrio da microbiota no intestino ou a uma maior disponibilidade dos nutrientes da dieta gerada por meio da degradação enzimática pela cepa probiótica, L. plantarum. Esta mesma cepa de bactéria ácido-láctica foi caracterizada in vitro quanto à produção de protease extracelular alcalina (1.170 $\mathrm{U} \mathrm{mg}^{-1}$ de proteína) e ácida $\left(3,8 \mathrm{U} \mathrm{mg}^{-1}\right.$ de proteína) (Souza, 2007). A alta produção da protease alcalina desta cepa pode explicar maiores valores de CDAPB e CDAE para camarões suplementados com L. plantarum.

Wang (2007)observou maior atividade enzimática em camarões alimentados com dieta contendo probióticos, o que melhorou a digestão de proteínas, carboidratos, lipídios e celulose. Efeitos similares foram descritos em peixes e camarões, em que as atividades enzimáticas aumentaram com o fornecimento de probióticos na dieta, o que ocasionou aumento da digestibilidade da dieta (Tovar-Ramírez et al., 2004; Ziaei-Nejad et al., 2006; Suzer et al., 2008; Zhou et al., 2009).

Com a intensificação da produção de camarões em cativeiro, aspectos nutricionais e sanitários devem ser priorizados para aperfeiçoar o processo produtivo e diminuir o risco de perda de produção por enfermidades. O uso de bactérias ácido-lácticas como aditivos probióticos na ração pode se tornar uma alternativa inovadora para a carcinicultura, pois além de trazer benefícios nutricionais ao hospedeiro, com um melhor

Tabela 3. Coeficientes de digestibilidade aparente de proteína bruta, matéria seca e energia de camarões marinhos, Litopenaeus vannamei, alimentados com dietas suplementadas ou não com o probiótico Lactobacillus plantarum.

\begin{tabular}{lcc}
\hline Coeficiente de digestibilidade aparente (\%) & Controle & Probiótico \\
\hline Matéria seca & $62,50 \pm 1,2$ & $63,30 \pm 0,23$ \\
Proteína & $82,73 \pm 1,01$ & $84,18 \pm 0,35^{(1)}$ \\
Energia & $78,63 \pm 0,93$ & $81,28 \pm 0,16^{(1)}$ \\
\hline
\end{tabular}

${ }^{(1)}$ Diferença significativa pelo teste t, a $5 \%$ de probabilidade. 
aproveitamento dos nutrientes da dieta, pode fortalecer o animal contra enfermidades bacterianas.

\section{Conclusão}

1. A coleta por decantação, baseada no modelo Guelph, é o método mais prático e eficiente para determinar o coeficiente aparente de digestibilidade da proteína bruta e da matéria seca, para Litopenaeus vannamei.

2. A suplementação da cepa probiótica Lactobacillus plantarum aumenta o coeficiente de digestibilidade aparente da proteína bruta e da energia da dieta para L. vannamei.

\section{Agradecimentos}

Ao Conselho Nacional de Desenvolvimento Científico e Tecnológico (CNPq), à Coordenação de Aperfeiçoamento de Pessoal de Nível Superior (Capes), ao Ministério da Pesca e Aquicultura (MPA) e à Empresa Brasileira de Pesquisa Agropecuária, pelo apoio financeiro e pela concessão de bolsas; e ao Laboratório de Nutrição de Organismos Aquáticos da Universidade Federal de Santa Catarina, especialmente a Renato Kitagima, pelo auxílio nas análises nutricionais.

\section{Referências}

BAUTISTA-TERUEL, M.N.; EUSEBIO, P.S.; WELSH, T.P. Utilization of feed pea, Pisum sativum, meal as a protein source in practical diets for juvenile tiger shrimp, Penaeus monodon. Aquaculture, v.225, p.121-131, 2003. DOI: 10.1016/ S0044-8486(03)00284-9.

BELAL, I.E.H. A review of some fish nutrition methodologies. Bioresource Technology, v.96, p.395-402, 2005. DOI: 10.1016/j. biortech.2003.11.030.

BREMER NETO, H.; GRANER, C.A.F.; PEZZATO, L.E.; PADOVANI, C.R.; CANTELMO, O.A. Diminuição do teor de óxido de crômio (III) usado como marcador externo. Revista Brasileira de Zootecnia, v.32, p.249-255, 2003. DOI: 10.1590/ S1516-35982003000200001.

BURR, G.; GATLIN, D.; RICKE, S. Microbial ecology of the gastrointestinal tract of fish and the potential application of prebiotics and probiotics in finfish aquaculture. Journal of the World Aquaculture Society, v.36, p.425-436, 2005. DOI: 10.1111/j.1749-7345.2005.tb00390.x.

CHO, C.Y.; COWEY, C.B.; WATANABE, T. Finfish nutrition in Asia: methodological approaches to research and development. Ottawa: International Development Research Centre, 1985. 154p.
COCKCROFT, A.; MCLACHLAN, A. Food and feeding habits of the surf zone penaeid prawn Macropetasma africanus (Balss). Marine Ecology, v.7, p.345-357, 1986. DOI: 10.1111/ j.1439-0485.1986.tb00169.x.

CRUZ-SUÁREZ, L.E.; TAPIA-SALAZAR, M.; VILLARREAL-CAVAZOS, D.; BELTRAN-ROCHA, J.; NIETO-LÓPEZ, M.; LEMME, A.; RICQUE-MARIE, D. Apparent dry matter, energy, protein and amino acid digestibility of four soybean ingredients in white shrimp Litopenaeus vannamei juveniles. Aquaculture, v.292, p.87-94, 2009. DOI: 10.1016/j. aquaculture.2009.03.026.

CUNNIFF, P. (Ed.). Official methods of analysis of AOAC International. $16^{\text {th }}$ ed. Washington: AOAC International, 1999. $1141 \mathrm{pp}$.

FAROONGSARMG, D.; CHANDUMPAI, A.; CHIAYVAREESAJJA, S.; THEAPPARAT, Y. Bioavailability and absorption analysis of oxytetracycline orally administered to the standardized moulting farmed Pacific white shrimps (Penaeus vannamei). Aquaculture, v.269, p.89-97, 2007. DOI: 10.1016/j. aquaculture.2007.04.019.

LAWRENCE, A.L.; LEE, P.G. Research in the Americas. In: D'ABRAMO, L.R.; CONKLIN, D.E.; AKIYAMA, D.M. (Ed.). Crustacean nutrition. Baton Rouge: World Aquaculture Society, 1997. p.566-587.

LEMOS, D.; LAWRENCE, A.L.; SICCARDI III, A.J. Prediction of apparent protein digestibility of ingredients and diets by in vitro $\mathrm{pH}$-stat degree of protein hydrolysis with species-specific enzymes for juvenile Pacific white shrimp Litopenaeus vannamei. Aquaculture, v.295, p.89-98, 2009. DOI: 10.1016/j. aquaculture.2009.06.011.

MARTÍNEZ-PALACIOS, C.A.; CABANILLAS-BELTRÁN, H.; PONCE-PALAFOX, J.T.; CHÁVEZ SÁNCHEZ, M.C.; ROSS, L.G. A modified chamber designed for estimation of digestibility in shrimp. North American Journal of Aquaculture, v.63, p.252-255, 2001. DOI: 10.1577/1548-8454(2001)063<0252:AMC $\mathrm{DFE}>2.0 . \mathrm{CO} ; 2$.

MOURIÑO, J.L.P.; DE STÉFANI, M.V. Avaliação de métodos de coleta de fezes para determinação da digestibilidade protéica em rã-touro (Rana catesbeiana). Ciência Rural, v.36, p.954-958, 2006. DOI: 10.1590/S0103-84782006000300035.

NOSE, T. On the digestion of food protein by goldfish (Carassius auratus, L.) and rainbow trout (Salmo irideus G.). Bulletin of Freshwater Fisheries Research Laboratory, v.10, p.11-22, 1960.

NUNES, A.J.P.; PARSONS, G.J. Size-related feeding and gastric evacuation measurements for the southern brown shrimp Penaeus subtilis. Aquaculture, v.187, p.133-151, 2000. DOI: 10.1016/ S0044-8486(99)00386-5.

OCHOA-SOLANO, J.L.; OLMOS-SOTO, J. The functional property of Bacillus for shrimp feeds. Food Microbiology, v.23, p.519-525, 2006. DOI: 10.1016/j.fm.2005.10.004.

SMITH, D.M.; TABRETT, S.J. Accurate measurement of in vivo digestibility of shrimp feeds. Aquaculture, v.232, p.563-580, 2004. DOI: 10.1016/j.aquaculture.2003.08.011. 
SOUZA, R.M. Influência na aplicação de bactéria ácido láctica na dieta sobre o cultivo de juvenis de robalo-peva (Centropomus parallelus Poey, 1860). 2007. 42p. Dissertação (Mestrado) Universidade Federal de Santa Catarina, Florianópolis.

SUZER, C.; COBAN, D.; KAMACI, H.O.; SAKA, S.; FIRAT, K.; OTGUCUOGLU, O.; KUCUKSARI, H. Lactobacillus spp. bacteria as probiotics in gilthead sea bream (Sparus aurata, L.) larvae: effects on growth performance and digestive enzyme activities. Aquaculture, v.280, p.140-145, 2008. DOI: 10.1016/j. aquaculture.2008.04.020.

TERRAZAS-FIERRO, M.; CIVERA-CERECEDO, R.; IBARRA-MARTÍNEZ, L.; GOYTORTÚA-BORES, E.; HERRERA-ANDRADE, M.; REYES-BECERRA, A. Apparent digestibility of dry matter, protein, and essential amino acid in marine feedstuffs for juvenile whiteleg shrimp Litopenaeus vannamei. Aquaculture, v.308, p.166-173, 2010. DOI: 10.1016/j. aquaculture.2010.08.021.

TOVAR-RAMÍREZ, D.; ZAMBONINO, I.J.; CAHU, C.; GATESOUPE, F.J.; VÁZQUEZ-JUÁREZ, R. Influence of dietary live yeast on European sea bass (Dicentrarchus labrax) larval development. Aquaculture, v.234, p.415-427, 2004. DOI: 10.1016/j.aquaculture.2004.01.028.

VIEIRA, F.N. do. Seleção e utilização de bactérias probióticas na carcinicultura marinha. 2010. 133p. Tese (Doutorado) Universidade Federal de Santa Catarina, Florianópolis.
VIEIRA, F.N. do; BUGLIONE NETO, C.C.; PEDREIRA MOURINO, J.L.; JATOBÁ, A.; RAMIREZ, C.; MARTINS, M.L.; BARRACCO, M.; VINATEA, L.A. Time related action of Lactobacillus plantarum in the bacterial microbiota of shrimp digestive tract and its action as immunostimulant. Pesquisa Agropecuária Brasileira, v.43, p.796-769, 2008. DOI: 10.1590/ S0100-204X2008000600013.

WANG, Y.B. Effect of probiotics on growth performance and digestive enzyme activity of the shrimp Penaeus vannamei. Aquaculture, v.269, p.259-264, 2007. DOI: 10.1016/j. aquaculture.2007.05.035.

YU, M.-C.; LI, Z.-J.; LIN, H.-Z.; WEN, G.L.; MA, S. Effect of dietary medicinal herbs and Bacillus on survival, growth, body composition, and digestive enzyme activity of the white shrimp Litopenaeus vannamei. Aquaculture International, v.17, p.377-384, 2009. DOI: 10.1007/s10499-008-9209-3.

ZHOU, X.-X.; WANG, Y.-B.; LI, W.-F. Effect of probiotic on larvae shrimp (Penaeus vannamei) based on water quality, survival rate and digestive enzyme activities. Aquaculture, v.287, p.349-353, 2009. DOI: 10.1016/j.aquaculture.2008.10.046.

ZIAEI-NEJAD, S.; REZAEI, M.H.; TAKAMI, G.A.; LOVETT, D.L.; MIRVAGHEFI, A.R.; SHAKOURI, M. The effect of Bacillus spp. bacteria used as probiotics on digestive enzyme activity, survival and growth in the Indian white shrimp Fenneropenaeus indicus. Aquaculture, v.252, p.516-524, 2006. DOI: 10.1016/j.aquaculture.2005.07.021.

Recebido em 13 de julho de 2011 e aprovado em 28 de fevereiro de 2013 